\title{
Translation and Practice Theory
}

Olohan, Maeve. 2020. Translation and Practice Theory. London: Routledge.

Reviewed by RAWAD ALHASHMI

Maeve Olohan's intellectual prowess can be attributed to her tireless academic endeavors and rigorous scholarly pursuits, which has resulted in several publications in the field of Translation Studies, including Introducing Corpora in Translation Studies (2004), Scientific and Technical Translation (2015), among others. In this regard, Olohan's Translation and Practice Theory is a step forward for her "Knowing in Translation Practice: A Practice-Theoretical Perspective." This article specifically focuses on 'knowing-inpractice' to address the linkage between practice and knowledge in translation, thereby offering a theoretical methodology anchored in the practice of translating rather than the content of translation or the translators' cognitive process (2017: 160).

Olohan's Translation and Practice Theory makes a salient contribution to the field of Translation Studies by covering key elements of translation practices that have been overlooked by translation theorists so far. She closely examines how freelance/professional translators perform their tasks, cope with challenges, interact with people, and use technology along with material objects in the workplace. In doing so, Olohan brings the character of translators onto the stage, capturing their breath, reading their minds, interpreting their body movements, and observing their environments - thereby encapsulating the active performance of translators in the workplace. According to Olohan, "the body performs translation, and the body interacts with other elements - things and people - in translating", thus providing clarity on "how 
body, mind, people, and objects are interwoven in practices" (2020: 3).

Against this backdrop, she introduces a practice theory for translation scholars based on a methodological and conceptual exploration of translating practices in the workplace attempting to gain a conceptual understanding of how things work at translation sites by examining the socio-material complexities of translation practice so as to expand the horizons of translation theory (2020: 5). Olohan's purpose is to offer a novel approach that enriches the discourse of translation theory through a practical lens to highlight its usefulness and efficacy.

\section{Chapters Overview}

The volume comprises an introduction and 8 chapters. In the introduction, she refers to Lina Mounzer's "Trash Talk: On Translating Garbage" (2019), which is highly relevant in navigating translation practices. Accordingly, Olohan employs Mounzer's account as a "springboard", to illuminate key elements of translating practice before delving deep into its theoretical exploration (3).

In chapter 1, From Product and Process to Practice Olohan traces the development of translation from the product, process-oriented approaches to a sociological paradigm. The latter emphasizes the role of the translator as an active agent, gradually shifting attention to empirical research, focusing on the translator's agency and the practice of translation on-site, thus configuring a practice-oriented apparatus by means of social practice.

In the second chapter Theorizing Practice, Olohan introduces the three-element model of practice: materials, competence, and meaning. To inform this conceptual approach, she explains how and why practices change and elaborates on the relationship between different practices. Such concepts of 
materials, competence and meaning represent integral aspects of the translating practices, which facilitates an understanding of her propound practice theory. Accordingly, she sharply examines the notion of social practice, and its usefulness to translation while exploring the role of the human body in translation, which comes across as an honest and genuine attempt.

Chapter 3 entitled Materials deals with the notion of the body as it performs various activities that are integral parts of translation practice. Here, she talks about interactions involving "body positions and movements, and potential consequences of bodily reconfigurations, come to the fore" (2020: 38). It is interesting that this chapter contains explanations of why the body and its actions constitute a key part of translation, offering plenty of resources for future translation enthusiasts.

In the fourth chapter, Competence, she draws attention to knowing the specific circumstances that constitute translating; especially pointing out the site of knowing is the practice. She claims that an approach based on practice poses questions concerning "know-how" specific to the practice, as such asking how a practice "constitute[s] the knowledge bases on which [its] continued existence depends" (2020: 62). To her credit, Olohan makes a clear distinction between the practice of learning and the practice of translating.

Chapter 5 titled Meaning draws on Schatzki's notions of general understandings, rules, and teleo-affectivity, as they constitute translation practices and "specify what should be said and done, to which, ends and with what emotions" (2020: 74). Olohan explains how the normative means by which translation practices are configured, formalized and standardized. In order to elaborate upon general understandings of professional translation, she collects a small 
corpus comprising 100 LSPs company services and discusses normative instruments that constitute the practice of translation.

In chapter 6 titled Connected Practices, Olohan illustrates the intersection between translation and other related practices. These interconnections are examined by focusing on "revising and reviewing, project management and vendor management while recognizing that the operations of the LSP constitute a fabric of many more interconnected practices" (2020: 90).

Chapter 7 titled Evolving Practices focuses on the integration of Post-Edits Machine Translations (PEMT) in translation practices. Olohan explains the manner in which the development of PEMT has directly affected the practice of translation regarding materials, competence, and meaning; thus, causing a significant change of understanding translation. She also refers to Translation Memory (TM) and Computeraided Translation (CAT) as productivity tools that have caused crucial changes in translation practice. This chapter primarily discusses technological tools that alter the paradigm of translation practice in the global market.

In the last chapter Researching Translation Practice, Olohan addresses approaches, challenges, and opportunities to assess practices related to translation (2020: 118). More specifically, she puts forward four research agendas aiming to stretch the horizons of translation theory. The first one concentrates on "specific sites where those practices are performed and reproduced" (2020: 129). The second is a genealogical approach, relating to the trajectory of a particular practice. Thirdly, the configurational method is associated with the interconnection between practices. This approach closely examines the link between translation and other related practices while defining the essence of that connection. The final approach is a dialectal one pertaining to the power 
imbalances and contradictions that cause practices to be in a state of flux. It also deals with the ramifications of translation practices (2020: 129).

\section{Critical Assessment}

Olohan's contribution is unique in that it advances an innovative perspective of understanding translation as a practical matter, especially with the growing technological involvement in translation machines, which directly impacts the practice of translation. In doing so, she propounds an alternative approach that considers the relationships between translation and other practices (2020: 89). Fundamentally, Olohan conceptually constructs a heavy-duty approach oriented toward the practice of translation with special emphasis on socio-material complexities. By orchestrating the activity of translation and the agency of the translator in carrying out the task of the translation, Olohan does a great job in capturing the mood and the intellectual capacity of the translators at the workplace through their physical body interaction with immediate surroundings. Another major strength is the palpable authentic experiences of the author, which is attributed to the fact that Olohan's account is based on her own empirical research. For example, she conducted about 250 hours of fieldwork observations as well as interviews with four language service providers (LSPs) to acquire a detailed understanding of practices related to translation and project management. Remarkably, Olohan draws a conceptual map toward a practice/practical turn by underling significant aspects involved in translation practice that are often ignored or downplayed. By focusing on the commercial and non-literary translation, the author showcases the effectiveness of her approach in understanding translation practice and coping with technology and other evolving challenges that have affected the practice of translation. 
According to Olohan, if the goal of Translation Studies is to explicate the role of translating practices, then these practices assume significance. To that end, Olohan broadens the spectrum of translation theory by making a trailblazing contribution.

Despite these apparent strengths, Olohan's text is not quite unblemished. To begin with, it is debatable as to why she criticizes the codes of ethics that govern the practice of professional translators' associations in the context of being ideal, faithful, authoritative, and professional. She argues, "The codes often revolve around an idealized notion of a faithful or accurate rendering, which, in turn, leads to unrealistic prescriptions that translators should not add to, omit or alter the ideas or form of the source text" (2020: 80). By offering this criticism, the author seems to underestimate the values of ethics in the profession without offering a credible, constructive, meaningful alternative that is equitable to translation practices. Although she assumes that her accounts of the general understandings of translation as common practice and a shared community purpose would be best suited as a standard of ethics, it may lead to unpredictable and less optimal outcomes. Notably, the code of ethics is not an assumption or inherent practice in translation; rather, the role of ethics in translation denotes a sense of responsibility and commitment to the profession and deserves great attention. Additionally, important issues such as the interplay of power and politics have been avoided by the author, and these issues would have been interesting to analyze, especially in a global context. Lastly, as far as the text's organization is concerned, it would be useful for readers if the author includes a section for literature review to discuss relevant scholarships in the subject matter, instead of using them as secondary sources in the chapters. These include but are not restricted to, Can Theory Help Translators?: A Dialogue Between the Ivory Tower and 
the Wordface (2002) by Emma Wagner, Andrew Chesterman, and Translation in Context edited by Andrew Chesterman, Natividad Gallardo San Salvador, and Yves Gambier.

Overall, Translation and Practice Theory presents a valuable resource in the realm of Translation Studies and makes a very welcomed contribution.

\section{Reference}

Olohan, Maeve. 2017. Knowing in Translation Practice: A Practice-theoretical perspective. Translation Spaces 6. 160181.

$$
\text { *** }
$$

\section{Cite This Work:}

Alhashmi, RaWAD. 2021. Translation and Practice Theory. Review of Translation and Practice Theory, by Maeve Olohan. Translation Today, Vol. 15(1). 247-253.

DOI:10.46623/tt/2021.15.1.br1 